\title{
LA EXPERIENCIA DEL MAL RADICAL EN LA OBRA DE JORGE SEMPRÚN THE EXPERIENCE OF RADICAL EVIL IN THE WORKS OF JORGE SEMPRÚN
}

\author{
RITA RODRÍGUEZ VARELA ${ }^{1}$ \\ Universidad
}

\begin{abstract}
Resumen
Este artículo pretende realizar un análisis de las novelas sobre los campos de concentración del escritor Jorge Semprún. Partiendo de la dicotomía escribir o vivir como un estado psicológico del autor tras su liberación, se reflexionará sobre las posibilidades de la literatura y del artificio como transmisores capaces de hacer entender la experiencia concentracionaria. Finalmente, se analizará el concepto filosófico del Mal Radical, señalado por Semprún como un elemento clave para entender dicha experiencia.
\end{abstract}

Palabras clave: artificio; campo de concentración; Mal Radical; memoria literaria; nazismo.

\begin{abstract}
This article analyses the writer Jorge Semprun's novels which the main topic is the concentration camps. Based on the dichotomy of writing or living as a psychological status of the writer after his release, this article will debate the ability of the literature as a way to transmit the essence of the concentration camps experience. To conclude, it will analyze the philosophic concept of the Radical Evil, identified by Semprun as a key element to understand that experience.
\end{abstract}

Keywords: artifice; concentration camp; Radical Evil; literary memory; Nazism.

Nacido en España, exiliado en Francia durante la Guerra Civil española, deportado al campo de Buchenwald durante la Segunda Guerra Mundial, militante clandestino del Partido Comunista durante la época franquista, ministro de cultura durante el gobierno de Felipe González, gran escritor... Jorge Semprún es, sin duda, tanto por la época en la que vivió como por su compromiso social y político, un gran testimonio más que español o francés, europeo, de los grandes sucesos del siglo XX. La lectura de su obra supone la lectura de la historia o, mejor dicho, su experimentación.

La escritura de Semprún nace de una decisión, nace de una toma de conciencia. Se trata de una escritura meditada que para su nacimiento necesitó plantearse una serie de cuestiones elementales; cuestiones que necesitaron, a su vez, de un tiempo de silencio y de olvido para poder ser respondidas. Era preciso cuestionarse si se podía

\footnotetext{
${ }^{1}$ Universitat de València Correo-e: rirova@alumni.uv.es. Recibido: 06-07-2017. Aceptado: 11-11-2017.
} 
contar la experiencia concentracionaria o, incluso, si se podía escuchar, cómo debía hacerse y por qué.

Este estudio pretende abarcar todas esas preguntas que recorren la obra concentracionaria del escritor. Para ello, se analizará la elección del escritor de permanecer en el silencio y las razones que lo llevaron a romperlo. A continuación, se mostrará cómo el artificio constituye un instrumento de transmisión capaz de involucrar al lector en la experiencia. Finalmente, se profundizará cómo retomando el viejo concepto del Mal Radical que alcanza su máxima expresión en los campos de concentración, el autor muestra nuevos matices derivados de su experiencia propia. Con la intención de llevar a cabo un análisis preciso, se utilizarán varias obras del autor, a saber Le grand voyage (1963), L'Écriture ou la vie (1994) y Se taire est impossible (1995).

Una vez liberado del campo de Buchenwald, a Semprún le persigue la idea o, más bien, la certitud de no haber sobrevivido a la muerte sino de haber sido atravesado por ella. La lectura de los testimonios que sobrevivieron a los campos de concentración así como de la dinámica de funcionamiento del nazismo, nos muestran como el objetivo principal es borrar cualquier característica de singularidad pues es un proceso de deshumanización: "la entrada en un campo de concentración (...) está marcada por el intento de borrar las señas de identidad; el nombre propio es sustituido por un número, la historia personal va desapareciendo ante el dolor y las vejaciones constantes" (Lorenzano, 2005: 234). En el nazismo no hay sitio para la singularidad, debe garantizarse la voluntad única. Todo se realiza con el propósito de borrar del hombre aquello que lo humaniza: separarlo de su familia, de su hogar y costumbres, de su nombre, privarlo de sueño, de agua, de comida... Así, el psiquiatra y ex-deportado Viktor Frankl explica que los hombres se convertían en un número y, por ello, "estar vivo o muerto carecía de importancia, porque la vida de un "número" resulta completamente irrelevante" (Frankl, 1979: 79). En este sentido, la denominación de campo de aniquilación cobra su máxima expresión tal y como señalaba Primo Levi:

Son los que pueblan mi memoria con su presencia sin rostro, y si pudiese encerrar todo el mal de nuestro tiempo en una imagen, escogería esta imagen que me resulta familiar: un hombre demacrado, con la cabeza inclinada y la espalda encorvada, en cuya cara y en cuyos ojos no puede leerse ni una huella de pensamiento (Levi, 1987: 99).

De esta lectura puede desprenderse que los campos de concentración producen dos tipos de cadáveres: los muertos y los vivos. Ante la sensación de ser un cadáver vivo, de haber sido atravesado por la muerte, Jorge Semprún reflexiona sobre lo que supone empezar el relato de lo vivido, sobre las consecuencias que conlleva permanecer en el recuerdo del horror; se cuestiona si es posible, en suma, escribir y seguir viviendo:

No lo consigo porque me doy cuenta muy rápidamente, bueno, me doy cuenta poco a poco, la decisión rápida, la decisión todavía es casi inconsciente, es una cosa de instinto más que de reflexión, de que escribir me mantiene en la memoria de la muerte, que para escribir tengo que estar todo el tiempo recapacitando, volviendo a sumergirme en aquella memoria. Y darme cuenta de que eso era mortal, literalmente mortífero, tú no sales vivo de esta, de este vivir en esa memoria. La única forma de salir de eso es olvidarte, aunque sea provisionalmente (Vilanova, 2006: 111-112). 
Estas declaraciones del autor nos desvelan que el título de la obra L'écriture ou la vie hace referencia a una situación psicológica del autor, donde escribir supone quedarse encerrado en la experiencia de la muerte y, por tanto, debe elegir entre la escritura o la vida, entre la memoria o el olvido, en definitiva, entre morir o vivir. La misma reflexión aparece de forma recurrente en muchos de sus libros, así en Federico Sánchez se despide de ustedes (1993) señala

La escritura me encerraba en la clausura de la muerte, me asfixiaba en ella, implacablemente. Había que escoger entre la escritura y la vida, y escogí esta última. Escogí una larga cura de afasia, de amnesia deliberada para volver a vivir, o para sobrevivir (Semprún, 1993: 29).

En efecto, Semprún no comienza a escribir hasta su estancia en la casa de la calle Concepción Bahamonde, donde Manuel Azaustre, militante comunista y antiguo prisionero político de Mauthausen, le cuenta su experiencia en el campo de concentración. El escritor entiende que narrada de esa forma nadie entenderá lo que supuso y, esa misma noche, empieza a escribir las primera líneas de su obra Le grand voyage. Si bien sobre la vivencia en los campos de concentración se pueden dar infinidad de testimonios, el autor no se plantea la necesidad de ser fiel a la realidad, no es veracidad lo que le falta al testimonio del antiguo deportado sino que no expresa lo esencial. Cuando en L'écriture ou la vie, el autor se pregunta si es posible contar esta experiencia no es por cuestiones de olvido, de falta de documentación o de testigos pues es algo que todavía está presente. Tampoco le son insuficientes las palabras, no se trata de algo indecible. Tras ser liberados, fueron muchos los que se replantearon si el lenguaje podía contenerlo todo, podía expresarlo todo pues "los presos fueron tratados con tal falta de dignidad y humanidad que muchos de los supervivientes se plantearon al intentar relatar lo vivido si el lenguaje convencional podía llegar a servir..." (Sánchez, 2011: 330). La cuestión básica es cómo expresar la sustancia, la densidad; cómo transmitir lo esencial de la experiencia concentracionaria.

Esta incesante búsqueda del autor conllevan la asunción de que la obra sempruniana no se basa en una escritura au tobiográfica que busque narrar las peripecias de su protagonista o que busque la auto-clarificación; se trata de una escritura testimonial cuyo imperativo es transmitir la esencia de lo que supuso para que los demás lo entiendan. Semprún escribe para ese "nosotros" que es la Humanidad. Se inscribe en la "memoria histórica" (Colmeiro, 2005: 17) de aquellos que vivieron la Segunda Guerra Mundial y pretende formar parte de la "conciencia histórica" (Colmeiro, 2005: 17) de las futuras generaciones. Cuando en su novela Le grand voyage, el personaje del viejo muere tras exclamar "Vous vous rendez compte?" (Semprún, 1963: 74), Semprún, a lo largo del libro, responderá "Mais oui, je me rends compte. Je ne fais que ça, me rendre compte et en rendre compte. C'est bien ce que je souhaite" (Semprún, 1963:78). El autor busca dar cuenta de ello utilizando como vehículo transmisor la escritura literaria. A pesar de que los historiadores no suelen conceder demasiado valor a los testimonios personales alegando cuestiones de subjetividad, de falta de rigor o de perspectiva; lo cierto es que, para conseguir transmitir lo que supuso, narrar con datos objetivos es insuficiente porque no estaremos transmitiendo la esencia. Es una literatura que "asume el difícil reto de cómo expresar lo indecible por inconcebible" (Espinosa, 2007: 
141). El escritor a través del artificio es el que puede arrojar claridad y expresar la sustancia. Se trata de la función del escritor como conciencia de la humanidad que señalaba Pérez de Ayala en su novela La pata de la raposa (1963): “Me parecía que usted había dado conciencia a mis ojos, a mis oídos, a mi corazón y a mi cerebro. Y ¿qué otra cosa es un escritor sino la conciencia de la humanidad?" (Pérez de Ayala, 1963: 415). En esta línea, el mejor escritor no será aquel que nos hable de la vida o de la muerte, sino aquel que nos haga sentirlas.

Por el mismo motivo, cuando Semprún presencia el visionado de unas imágenes sobre los campos de concentración no reconoce en ellas su vivencia. Las imágenes eran fieles, mostraban la verdad de lo sucedido pero estaban vacías de contenido:

Les images, en effet, tout en montrant l'horreur nue, la déchéance physique, le travail de la mort, étaient muettes. (...) Muettes surtout parce qu'elles ne disaient rien de précis sur la réalité montrée, parce qu'elles n'en laissaient entendre que des bribes, des messages confus. Il aurait fallu travailler le film au corps, dans sa matière filmique même, en arrêter parfois le défilement : fixer l'image pour en agrandir certains détails ; reprendre la projection au ralenti, dans certains cas, en accélérer le rythme, à d'autres moments. Il aurait surtout fallu commenter les images, pour les déchiffrer, les inscrire non seulement dans un contexte historique mais dans une continuité de sentiments et d'émotions. Et ce commentaire, pour s'approcher le plus près possible de la vérité vécue, aurait dû être prononcé par les survivants eux-mêmes : les revenants de cette longue absence, les Lazares de cette longue mort. Il aurait fallu, en somme, traiter la réalité documentaire comme une matière de fiction (Semprún, 1994 : 261-262).

La simple proyección de escenas o la narración irreflexiva y desordenada de los hechos son incapaces de transmitir al receptor la esencia. Además, al tratarse de la expresión de unos hechos difícilmente concebibles y creíbles para el receptor, ha de hacerse un esfuerzo superior para darles credibilidad. Semprún se interroga "sobre la comunicabilidad de la experiencia del mal, sobre la necesidad de dotar al relato de una estructura temporal y narrativa totalmente elaborada que fuera mucho más que un conjunto de acontecimientos..." (Pla, 2010: 134). Es preciso realizar un trabajo de reflexión para repensar la realidad y recrearla. En este sentido, el artificio de la literatura actúa supliendo las carencias: "para ese propósito, ir más allá de la Historia académica, la memoria fáctica no basta, es insuficiente, será preciso una memoria literaria, capaz de poner la imaginación al servicio de la verdad" (Fernández, 2004: 85). Esta postura implica la fidelidad no a lo literalmente ocurrido, sino a su verdad esencial. Como indica Sánchez Zapatero (2010) al igual que en El Guernica de Picasso no existe una correspondencia formal entre la realidad y la plasmación de dicha realidad pero nadie puede negar su valor y su capacidad de transmisión de la experiencia del horror, el articifio de la literatura es capaz de transmitir una verdad que pueda conmover al lector. Ya Aristóteles en su Poética (2011) explicaba que la virtud y la perfección poética se daban gracias a la capacidad de conmover a los espectadores al generarles sentimientos análogos a los que producen los hechos reales junto al placer estético. En este caso, la plasmación sistemática de la realidad no transmite suficientemente bien la tragedia de los acontecimientos:

La sinceridad del militante era indiscutible, pero "su verdad ya ni siquiera resultaba verosímil". No bastaba con contar lo que pasó. Había que seleccionar, eliminar, poner en perspectiva, 
recrear, trabajar la realidad, en definitiva, poner un poco (o mucho) de artificio, de ficción (Pla, 2010: 134-135).

Unos acontecimientos casi irreales, que necesitan del artificio para poder ser percibidos como verosímiles por el lector y lograr conmoverlo.

El artificio sempruniano bebe de diferentes fuentes de inspiración para ejecutar su misión. Podría nombrarse en primer lugar la creación del personaje del chico de Semur en su obra Le grand voyage. El autor explica la necesidad de dicho artificio de la siguiente manera:

J'ai inventé le gars de Semur pour me tenir compagnie, quand j'ai refait ce voyage dans la réalité rêvée de l'écriture. Sans doute pour m'éviter la solitude qui avait étéla mienne, pendant le voyage réel de Compiègne à Buchenwald. J'ai inventé le gars de Semur, j'ai inventé nos conversations : la réalité a souvent besoin d'invention, pour devenir vraie. C'est-à-dire vraisemblable. Pour emporter la conviction, l'émotion du lecteur (Semprún, 1994 : 336-337).

La desilusión que produjo en muchos lectores el descubrimiento de que el chico de Semur era ficticio, da muestra del impacto que genera este personaje. Sin este producto del artificio, el relato de Semprún quizá no habría conseguido llegar hasta el lector y conmoverlo, quizá no habría despertado tanta emotividad en el lector. Y, dicha emotividad, es imprescindible para que su mensaje tenga un calado real. Por otro lado, la interacción entre Semprún y el chico de Semur es la que los singulariza y los diferencia del resto de personas prácticamente inertes y amontonadas que viajaban en el mismo vagón. Esta interacción ficticia transmite, además, el ejercicio de reflexión que Semprún cosechó durante su largo silencio. Unas reflexiones que se muestran al lector dentro de una dinámica más activa al producirse dentro de un diálogo y no sólo como pensamiento estático del narrador.

Otra fuente en la que se recrea el artificio sempruniano es la pintura y la escultura como fondos de cultura comunes al escritor y al lector. Refiriéndose y evocando obras artísticas presentes en el imaginario colectivo, Semprún traslada al lector a la experiencia misma. Un ejemplo de ello sería la asociación de los cuerpos de los difuntos y de los detenidos a los cuadros del Greco:

Il n'y avait que des regards morts, grands ouverts sur l'horreur du monde. Les cadavres, contorsionnés comme les figures du Greco, semblaient avoir ramassé leurs dernières forces pour ramper sur les planches du châlit jusqu'au plus près du couloir central de la braque, par oú aurait pu surgir un ultime secours. Les regards morts, glacés par l'angoisse de l'attente, avaient sans doute guetté jusqu'à la fin quelque arrivée subite et salvatrice. Le désespoir qui y était lisible était à la mesure de cette attente, de cette ultime violence de l'espérance (Semprún, 1994 : 43-44).

La fuerza de las referencias artísticas testimonia el hecho de que, como señala Mukarovsky (1970), la obra de arte no puede ser identificada únicamente con su autor o con su receptor sino que, al contrario, está destinada a servir de intermediaria entre el autor y la colectividad, es su misión primera. De igual forma, las esculturas de Giacometti poseen una gran fuerza evocadora por lo que detonarán la invasión sensitiva haciendo que el autor reviva la experiencia incesantemente, traspasando las fronteras de lo temporal y lo circunstancial: 
Jamais, plus tard, toute une vie plus tard, je ne pourrais éviter la bouffée d'émotion (...) d'émotion rétrospective, morale, pas seulement esthétique, que susciterait en tous lieux la contemplation des promeneurs de Giacometti, noueux, l'oeil indifférent dressé vers des cieux indécis, infinis, déambulant de leur pas inlassable, vertigineusement immobile, vers un avenir incertain, sans autre perspective ou profondeur que celle que créerait leur propre démarche aveugle mais obstinée (Semprún, 1994 : 66).

Estos paseantes de ojo indiferente y constitución raquítica trasladan al autor, independientemente de la situación en la que se encuentre, al campo de Buchenwald. Provocan en él el recuerdo de las siluetas de los deportados, cadáveres vivos de mirada perdida, que paseaban sin rumbo con sus piernas esqueléticas "dans un mouvement imperceptible de sonambules" (Semprún, 1994: 65).

Una vez respondidas las preguntas de si debe contarse y cómo, conviene ahora abordar qué es lo esencial de la experiencia concentracionaria.

Si en el pensamiento antiguo predominó la reflexión en torno al ser y al devenir del ser, es evidente que en el siglo XX, a causa de sus hechos históricos, predomina la pregunta sobre el mal. Así, según Semprún, los campos de concentración nos indican la dirección sobre la que es preciso indagar:

L'essentiel, dis-je au lieutenant Rosenfeld, c'est l'expériencia du Mal. Certes, on peut la faire partout, cette expériencie... Nul besoin des camps de concentration pour connaître le Mal. Mais ici, elle aura été cruciale, et massive, elle aura tout envahi, tout dévoré... C'est l'expérience du Mal radical... (Semprún, $1994: 120$ ).

El concepto del Mal Radical fue abordado por el filósofo Immanuel Kant por primera vez en su ensayo Sobre el mal radical en la naturaleza humana (1792) y, posteriormente, en La religión dentro de los límites de la razón (1793). Conviene aclarar que el Mal Radical no es un tipo de mal y no tiene que ver con las inclinaciones naturales del ser humano, ni con su naturaleza sensible y fenoménica, ni con el cuerpo, sus necesidades y deseos ni es, tampoco, un defecto o corrupción intrínseco a la razón humana. El Mal Radical está ligado, al contrario, a la corrupción de la voluntad. Como señala Bernstein,

... lo que designa es la propensión (Hang) a no hacer lo que el deber manda, a no obedecer la ley moral. De hecho, Kant utiliza el adjetivo radikal para calificar el Böse con el fin de señalar que dicha propensión tiene sus raíces en la naturaleza humana, y más específicamente, en la corrupción de la voluntad (Willkür); apela, así, al sentido etimológico, original del término radikal (Bernstein, 2005: 51).

Por ello, si lo esencial de la experiencia concentracionaria es la experiencia del Mal Radical, la esencia de lo que pretende transmitir Semprún es que este Mal Radical tiene el mismo origen que el Bien Radical, ambos son fruto de la elección libre del hombre. Como explica el autor en Se taire est impossible: "On arrive au noyau même, au centre même de l'expérience des camps. C'est-à-dire la découverte que la liberté humaine, la liberté de l'homme est une liberté capable du Bien et du Mal" (Semprún, 1995: 24). En este sentido, se pretende acabar con la justificación divina del Bien y del Mal o con justificaciones de impulso o apetito. Como señala Ouaknin (2001) no es Dios el que murió en Auschwitz, es el hombre. En la voluntad del hombre es donde se encuentra el lugar originario de la maldad y de la bondad, por tanto, la naturaleza no 
tiene la culpa o el mérito de nuestros actos, tampoco Dios. Sólo el hombre es el autor y, por ello, el responsable. El Bien y el Mal son las máximas de la volición humana.

A lo largo del siglo XX, a causa de los acontecimientos históricos, son numerosos los autores que abordan el concepto del Mal Radical desde diferentes perspectivas. Así, por ejemplo, Levinas aboga por resistir la tentación de justificar el sufrimiento inútil. Si interpreto que la economía se basa en que el bien sea el contrapeso del mal, actúo en un marco operativo dónde hay una economía de relaciones simétricas. No obstante, la respuesta al mal del siglo XX es asumir mi responsabilidad más allá de la reciprocidad, en la asimetría relacional con los otros. También, el filósofo Jonás defenderá el sí a la vida como valor básico inherente a la vida orgánica. Esta reafirmación básica busca trasladarnos del ser al deber: los humanos tiene el imperativo de preservar la vida tanto para el presente como para el futuro; y ello, en términos de sentimientos para que pueda ser convertido en una fuerza impulsora.

En líneas generales, todos los autores que reflexionan y repiensan el significado del Mal como un exceso inasimilable de forma adecuada al entendimiento humano.

En este sentido, explica Semprún, su decisión de romper el silencio no responde a una necesidad hacia él mismo sino hacia los otros:

Das une courte préface, Jorge Semprun dit cet essentiel auquel on ne peut que souscrire : " (J'ai parlé) pour dire que nous ne pouvions nous satisfaire de la rhétorique d'une commémoration pleine de compassion et de complaisance... pour aider cette jeunesse à s'orienter dans les luttes d'aujourd'hui contre la purification ethnique et les intégrismes de toute espèce, les orthodoxies de la pensée correcte (Schweitzer, 1996 : 149).

Se trata de enviar un mensaje claro y comprensible. Lo cierto es que, aunque señale que el hombre es el culpable primero y último de lo sucedido, abre también un camino a la esperanza: el mal es un fenómeno espiritual, consustancial de la humanidad del hombre pero el bien lo es igualmente.

Y este camino hacia la esperanza no debe ser forjado con términos genéricos o abstractos sobre el concepto del Mal Radical. Al contrario, debe basarse en actuaciones concretas que han dejado un registro en la historia. En esta línea, conviene retomar las ideas de Ortega y Gasset quien explica que el hombre empieza a existir sobre cierta altitud de pretérito, razón por la cual no es nunca un primer hombre. Dicho pretérito se conforma como el único tesoro del ser humano, independientemente de lo que de él sea acertado o merezca conservación. Lo trascendental es esa memoria de los errores que nos permite no cometer los mismos siempre: "El verdadero tesoro del hombre es el tesoro de sus errores, la larga experiencia vital decantada gota a gota. Por eso Nietzsche define el hombre superior como el ser de la más larga memoria" (Ortega y Gasset, 2009: 69).

Para concluir, conviene señalar que la mayor parte de los escritores que fueron víctimas del nazismo y sufrieron la experiencia de los campos de concentración sintieron, tras su liberación, una necesidad urgente de escribir y relatar lo sucedido. No obstante, el presente estudio ha abordado el caso de Jorge Semprún, un escritor que, al contrario, necesitó permanecer en el silencio y en el olvido pues hablar o escribir 
sobre lo sucedido conllevaba mantenerse constantemente en el recuerdo del horror. El estudio de sus relatos concentracionarios ha permitido entender cómo, para Semprún, la elección entre la escritura o la vida era una elección vital. Tal y como se ha señalado, la decisión de romper el silencio no responde a una necesidad del escritor hacia sí mismo sino hacia los otros:

Entre los que escriben su testimonio, no sólo pretenden aportar un simple dato de la realidad, válido por sí mismo, sienten la necesidad de explicar o justificar su doble audacia de haber vivido y de hablar después y solicitan que su escrito se haga público y que los demás lo lean. Buscan, además de impulsar el conocimiento, la reacción de sus contemporáneos y de las generaciones siguientes en un grito de "nunca más". ¡No olvidar! y recordar es el imperativo bíblico que se hace carne y letra ante la experiencia de la muerte en masa (Cuesta, 1998: 87).

Semprún decide empezar a escribir con el propósito de que los lectores puedan entender la esencia de la experiencia concentracionaria y evitar su repetición. Para tal empresa, una escritura estrictamente fiel a la realidad carece de la capacidad de conmover e implicar al lector, es necesario hacer uso del artificio. Leer los relatos concentracionarios conlleva "(re)vivir ahora y aquí el horror, el mal radical" (Mèlich, 2001: 24). La objetividad se posiciona en un plano secundario dejando paso a la expresión de la vivencia por eso "en la lectura del relato, el lector vive la experiencia del horror y su identidad sufre un vuelco, se transforma" (Mèlich, 2001: 31).

En líneas anteriores se ha explicado la poca credibilidad que los historiadores tienden a conceder a los relatos testimoniales pero conviene señalar que sin ese trabajo de reflexión, creación y recreación de la realidad, el relato no tendría la suficiente fuerza evocadora, perecería en su intento de convertirse en una fuerza de cambio:

... el arte representativo aspira (...) a desvelar ante nosotros la verdad del mundo. Cuando la historia sirve al poeta de punto de partida para sus ficciones, puede tomarse libertades en relación con el desarrollo exacto de los hechos, pero sólo con la intención de revelar su esencia escondida: aquí estriba la superioridad de la poesía sobre la historia, (...) la obra de arte es también una afirmación de valores; testimonio un compromiso moral y político... (Todorov, 2004: 278).

Sin este intento de difusión de la esencia gracias a la fuerza y las posibilidades que otorga el arte, quizá no se transmitiría un mensaje clave para las futuras generaciones. A saber, si lo esencial fue la experiencia del Mal Radical y éste es un fenómeno humano, nada puede asegurarnos que no se vuelva a repetir. Los relatos semprunianos no tienen únicamente como objetivo narrar y explicar en qué consistían los campos de concentración, lo que supusieron; no son relatos que hablen sólo del pasado sino que tienen, también, un mensaje para el futuro. El autor intenta explicar que depende del hombre ser bueno o malo según adopte máximas de acción buenas o malas. Por ello, a pesar de que señale que el hombre es el único culpable de toda la maldad producida y, por tanto, puede seguir produciéndola en el futuro, el autor abre también un camino a la esperanza pues “Le mal n'est ni le résultat ni le résidu de l'animalité de l'homme: il est un phénomène spirituel, consubstantiel de l'humanité de l'homme. Mais le bien l'est tout autant"' (Semprún, 1995: 28).

Semprún al igual que el filósofo Ortega y Gasset, inciden sobre el hecho de que el hombre no tiene naturaleza sino historia; solo la historia es la realidad del hombre. 
En este sentido, negar el pasado no tiene lógica pues siempre vuelve como un trauma no elaborado. Los autores nos invitan a integrar nuestro pasado, nuestra historia en el presente para poder aprender de él, superarlo y evolucionar. Como ya indicaba Primo Levi (2005) muchos sobrevivientes escribieron sus vivencias porque no quieren ni pueden olvidar pero, sobre todo, para que el mundo no olvide porque no se trata de un paréntesis en la evolución del hombre; es preciso entender las causas, las razones que se esconden detrás, desenmascarar la esencia de lo vivido para evitar su repetición:

... han entendido que su experiencia no ha sido sin sentido, y que el Lager no es un accidente, un imprevisto en la Historia. (...) Los Lager nazis han sido el ápice, la coronación del fascismo en Europa, su manifestación más monstruosa; pero el fascismo existía antes de Hitler y Mussolini, y ha sobrevivido en formas abiertas o enmascaradas a la derrota de la segunda guerra mundial. En todas las partes del mundo, allí donde se comienza con el negar la libertades fundamentales del Hombre, la igualdad entre los hombres, se va hacia un sistema concentracionista y ésta es una vía en la cual es difícil detenerse (Levi, 2005: 35-36).

El deseo de volver sobre el pasado y repensarlo, la necesidad de Semprún de escribir su vivencia y hacer énfasis en la imposibilidad de olvidar lo ocurrido no ansía anclar al hombre en el recuerdo de sus acciones para castigarlo y condenarlo. El hombre, al contrario del animal, posee la gracia de la conciencia histórica y, por ello, sus errores y su pasado se conforman como un gran tesoro. A partir de su determinada realidad social e histórica funciona la razón vital del sujeto concretizándose en razón histórica. Se trata de la búsqueda de aquello que posibilita y vuelve inteligible al hombre como ser histórico. Y dicha búsqueda debe ser continua, la racionalidad de la historia se constituye al rehacer esquemas bajo el signo de la prueba y del error:

... la realidad histórica, el destino humano avanza dialécticamente, si bien esa esencial dialéctica de la vida no es, como creía Hegel, una dialéctica conceptual, de razón pura, sino precisamente la dialéctica de una razón mucho más amplia, honda y rica que la pura - a saber, la de la vida, la de la razón viviente (Ortega y Gasset, 1933: 135).

Por lo tanto, la razón histórica no debe anclarse en el estatismo, ha de ser móvil como la realidad que pretender aprehender. Ello sólo se logra viviendo y reviviendo dicha realidad, es decir, siendo una razón viviente.

Esta investigación comenzó afirmando que la escritura de Jorge Semprún nace de una toma de conciencia individual pero cabe mencionar también que pretende formar parte de la conciencia colectiva. Los sucesos que narra el autor, las ideas sobre las que reflexiona son parte de la memoria colectiva, son parte de una historia común. Por todo ello, su obra es un testimonio y un documento clave para el entendimiento de algunos de los trágicos sucesos que atravesaron el siglo XX.

\section{BIBLIOGRAFÍA}

Bernstein, J. R. (2005): El mal radical. Una indagación filosófica, Buenos Aires, Ediciones Lilmod.

Colmeiro, J.F. (2005): Memoria histórica e identidad cultural: de la posguerra a la postmodernidad, Barcelona, Anthropos. 
Cuesta Bustillo, J. (1998): “La memoria del horror, después de la II guerra mundial”, en Ayer, $N^{0}$ 32, Memoria e historia, pp. 81-104.

Espinosa Domínguez, C. (2007): “El poeta del Infierno Congelado", en Renacimiento, $N^{o} 55 / 58, p p .141-152$.

Fernández, C. (2004): “Estrategias de la memoria en la obra de Jorge Semprún", en Historia, Antropología y Fuentes Orales, N³2, Entre Fábula y Memoria, pp.69-87.

Frankl, V. (1979): El hombre en busca de sentido, Barcelona, Herder.

Levi, P. (1987): Si esto es un hombre, Barcelona, Austral.

Levi, P. (2005): Entrevista a sí mismo, Buenos Aires, Leviatán.

Lorenzano, S. (2005): “Memorias del horror o Susan Sontag como pretexto", en Debate Feminista, Vol. 31, pp. 231-241.

Mèlich, J.C. (2001): La ausencia del testimonio. Ética y pedagogía en los relatos del Holocausto, Barcelona, Rubí.

Mukarovsky, J. (1970): “L'art comme fait sémiologique”, Poétique 3, pp.387-392.

Ortega y Gasset, J. (2009): La rebelión de las masas, Barcelona, Espasa.

Ortega y Gasset, J. (1933): En torno a Galileo, Madrid, Tecnos.

Ouaknin, M.A. (1998): Tsimtsoum. Introduction à la meditation hébraïque, París, Albin Michel.

Pla, X. (2010): “Jorge Semprún, la densidad transparente y la verdad literaria”, en Jorge Semprún o las espirales de la memoria, ed. Xavier Pla, Kassel, Reichenberger.

Pérez de Ayala, R. (1963): “La pata de la raposa”, en Obras completas, de. José García Mercadal, Madrid, Aguilar.

Sánchez Zapatero, J. (2010): Literatura y campos de concentración, España, Montesinos.

Sánchez Zapatero, J. (2011): “La representación de la experiencia concentracionaria: un caso de literatura universal", en Anuario de literatura comparada, 1, pp.325-337.

Schweitzer, S. (1996): "Soleils noirs de la déportation", en Vingtième Siècle. Revue d'histoire, $N^{\circ} 49$, pp.148-149.

Semprún, J. (1963): Le grand voyage, París, Gallimard.

Semprún, J. (1993): Federico Sánchez se despide de ustedes, Barcelona, Tusquets Editores.

Semprún, J. (1994): L'écriture ou la vie, París, Gallimard.

Semprún, J. (1995): Mal et modernité, París, Climats.

Semprún, J., Wiesel, E. (1995): Se taire est impossible, París, Éditions Mille et une nuits.

Trueba, C. (2004): Ética y tragedia en Aristóteles, México, Anthropos.

Todorov, T. (2004): Frente al limite, Buenos Aires, Siglo XXI.

Vilanova, M. (2006): “Jorge Semprún, París 2005”, en Historia, Antropología y Fuentes Orales, No35, Utopía y Contrautopía, pp.105-117. 